\title{
Dissemination of tumour cells from fine needle biopsy
}

\author{
N REDWOOD, D BEGGS, W E MORGAN \\ From the Department of Thoracic Surgery, City Hospital, Nottingham
}

\begin{abstract}
A 53 year old woman developed a cutaneous tumour implant in the needle track after transcutaneous fine needle biopsy of a pulmonary adenocarcinoma. The tumour implant was completely excised.
\end{abstract}

The value of fine needle biopsy in the diagnosis of discrete lung shadows seen on chest radiographs is firmly established. ${ }^{12}$ The procedure is not, however, entirely without immediate or long term risk.

\section{Case report}

A nervous 53 year old housewife presented with joint pains, a dry cough, and a chest radiograph showing a left upper zone mass. Computed tomography showed the mass to be irregular, $3 \mathrm{~cm}$ in diameter, and in the periphery of the left upper lobe. There was no evidence of enlarged mediastinal nodes or invasion of local structures. Despite the typical appearances of a primary carcinoma of the lung, the patient would not consider thoracotomy without histological proof of malignancy and consequently a fine needle biopsy was performed by an experienced radiologist, using a 20 gauge screw biopsy needle and an anterior approach. The procedure was difficult as the patient's cooperation was poor and both histological and cytological appearances were inconclusive. The patient eventually agreed to thoracotomy two months later and the left upper lobe was removed. Subsequent histological examination showed a completely excised, poorly differentiated adenocarcinoma.

Two months after leaving hospital the patient was referred back with a painful and rapidly enlarging lump on her anterior chest wall (figure). This had appeared at the exact site of puncture for the fine needle biopsy and seemed to be attached to the scar from the biopsy. A wide surgical excision of this lesion was performed. Histological examination of the resected specimen showed invasion of subcutaneous fat by a metastatic, poorly differentiated adenocarcinoma identical in appearance to that removed from the lung two months previously. Excision was complete.

The patient remained symptom free until her death, one year later, from a myocardial infarct. Necropsy showed no evidence of recurrence of the tumour.

Address for reprint requests: Dr N Redwood, Department of Thoracic Surgery, City Hospital, Nottingham NG5 1PB.

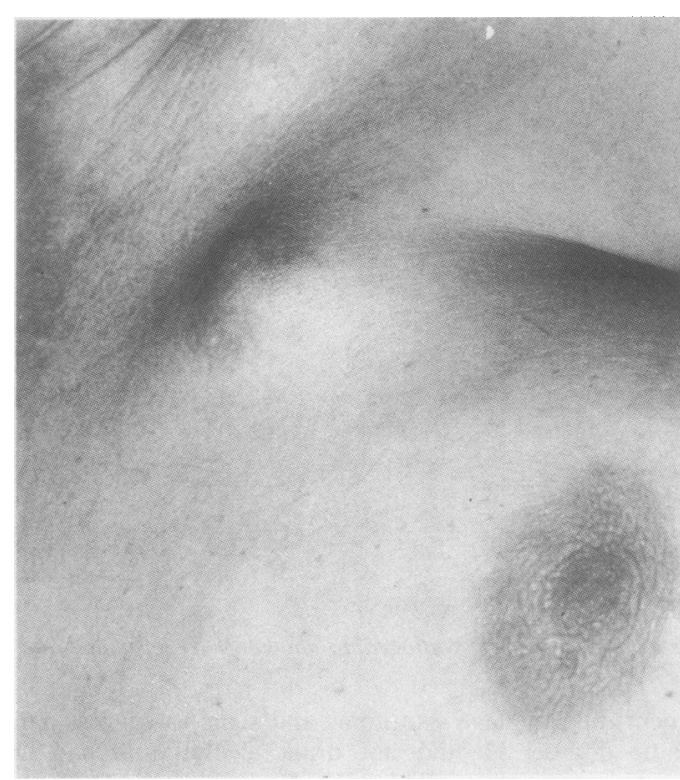

Painful lump on the chest wall at the site of puncture.

\section{Discussion}

Percutaneous transthoracic needle biopsy of pulmonafy lesions under radiological control is a relatively simple procedure that causes the patient little discomfort. The complication rate is low and the diagnostic accuracy is good There remains, however, the theoretical risk of implantation metastasis along the needle track. Sinner and Zajicek ${ }^{3}$ foung only one such case in 1264 patients who underwent needle biopsy. Their review of published reports suggested that the theoretical risk of tumour dissemination did not influenes survival. Struve-Christensen ${ }^{4}$ showed experimentally that malignant cells could be found in $89 \%$ of needle biop tracks, but that this produced a clinically significant lesion $\mathrm{m}$ only $0.04 \%$ of cases, again emphasising the safety of the tesp There have only been two previous reports of seeding malignant cells from lung carcinoma.

This is the only example of a needle track implantation $\frac{\text { an }}{\text { an }}$ this hospital, where over $\mathbf{4 0 0}$ fine needle biopsies of luof lesions have been performed in the last four years. 


\section{References}

1 Veale D, Gilmartin JJ, Sumerling MD, Wadehra VW, Gibson GJ. Prospective evaluation of fine needle aspiration in the diagnosis of lung cancer. Thorax 1988;43:540-4.

2 Lees WR, Hall-Craggs MA, Manhire A. Five years' experience of fine-needle aspiration biopsy: 454 consecutive cases. Clin Radiol 1985;36:517-20.

3 Sinner WN. Complications of percutaneous transthoracic needle aspiration biopsy. Acta Radiol [Diagn] (Stockh) 1976;17: 813-27.

4 Struve-Christensen E. Iatrogenic dissemination of tumour cells. Dissemination of tumour cells along the needle track after percutaneous transthoracic lung biopsy. Dan Med Bull 1978;25:82-7.

5 Muller NL, Bergin CJ, Miller RR, Ostrow DN. Seeding of malignancy cells into the needle track after lung and pleural biopsy. J Can Ass Radiol 1986;37:192-4. 